\title{
Identification of functional modules induced by bare-metal stents and paclitaxel-eluting stents in coronary heart disease
}

\author{
ZHAOBIN TANG $^{1}$, JINGJING GU ${ }^{2}$, PING SUN $^{2}$, JING ZHAO $^{3}$ and YONGGANG ZHAO ${ }^{1}$ \\ ${ }^{1}$ Cardiology Second Ward, The First Hospital of Zibo; ${ }^{2}$ Department of Pharmacy, The Fourth People's Hospital of Zibo; \\ ${ }^{3}$ Medical Record Management Section, The First Hospital of Zibo, Zibo, Shandong 255200, P.R. China
}

Received July 24, 2017; Accepted January 15, 2018

DOI: $10.3892 /$ etm.2018.5879

\begin{abstract}
Bare-metal stents (BMS) and paclitaxel-eluting stent (PES) are frequently used in medicine for the treatment of coronary heart disease, with millions of patients treated worldwide. The protein-protein interactions (PPI) were adopted to construct the networks. The M-module algorithm was used to identify multiple differential modules. Gene Ontology enrichment and pathway enrichment analysis were performed to analyze characteristics of modules. With the PPI and microarray data, two differential co-expressed networks were constructed, module 1 indicating PES and module 2 indicating BMS, with the same genes but different edges. At a module connectivity dynamic score P-value cut-off of $<0.05$, module 1 was identified with 142 nodes and 460 edges and in the module 2, 73 nodes and 222 edges were identified. Significant biological processes and pathways were found different in the two modules. Through the two differential modules, we revealed the potential molecular changes induced by PES and BMS providing new insights into the underlying mechanisms in human left internal mammary arteries after inserted with a stent.
\end{abstract}

\section{Introduction}

The introduction of stent by Puel and Sigwart in clinical practice marked a new era in operational cardiology (1). Bare-metal

Correspondence to: Dr Zhaobin Tang, Cardiology Second Ward, The First Hospital of Zibo, 4 Emeishan Eastern Road, Zibo, Shandong 255200, P.R. China

E-mail: ymu916@163.com

Abbreviations: BMS, bare-metal stents; PES, paclitaxel-eluting stent; LIMA, left internal mammary artery; M-DM, multiple differential modules; DES, drug-eluting stents; FDR, Food and Drug Administration; CAD, coronary artery disease; DCNs, differential co-expression networks; GO, gene ontology; RMA, robust multichip average; PM, perfect match; MM, mismatch; KEGG, Kyoto Encyclopedia of Genes and Genomes

Key words: bare-metal stents, left internal mammary artery arteries, module, paclitaxel-eluting stents, pathway stents (BMS) or drug-eluting stents (DES) are frequently used in medicine, with millions of patients treated worldwide $(2,3)$. The use of DES has been shown more effective than BMS in the reduction of restenosis (4). In particular, paclitaxel-eluting stent (PES) has been shown remarkably effective compared with BMS. PES has been approved by the US Food and Drug Administration for treating coronary artery disease (CAD) (5), although it is now rarely used in the US and Europe due to the superiority of second-generation stents (zotarolimus and everolimus-eluting stents) (6). The purpose of this study was to compare the putative molecular mechanism induced by PES and BES in denuded human left internal mammary arteries (LIMA).

Network biology has been applied to study cardiovascular diseases, such as coronary heart disease (7) atherosclerosis (8) and heart failure (9). Understanding the molecular networks may provide important insights into the effect of PES and BMS in LIMA. Several methods have been developed to construct gene regulator networks or modules, including Bayesian probabilistic network method (10), Genetic Network Expansion SYStem (11) and Minreg method (12). The iMDM algorithm is another method to identify both unique and shared gene modules across multiple differential co-expression networks (DCNs) (13). This method showed higher accuracy in inferring genes and modules compared with other method. In multiple conditions, the multiple differential modules (M-DMs) algorithm revealed dynamic changes in both gene activity and connectivity (13).

To date, microarrays have been a powerful tool to analyze gene expression levels and gene functions (14). MicroRNA microarrays have been used to explore the role of miRNA in different pathophysiological states. miRNA expression was first used to construct networks to identify important miRNA cliques (15). Besides, miRNA microarray can be used to investigate functional links between miRNAs by analyzing conserved miRNA co-expression relationships (16).

In the present study, we applied iMDM algorithm to analyze microarray data to compare molecular mechanism in LIMA induced by PES and BMS. We constructed DCNs by mapping genes to protein-protein interaction (PPI) data. The iMDM algorithm was used to identify differential modules. The Gene Ontology (GO) and pathway were applied for enrichment analysis. This method may provide new insights to the comparison of BMS and PES in LIMA. 


\section{Materials and methods}

\section{Datasets}

Gene expression data. Microarray gene expression data of E-GEOD-19136 was obtained from ArrayExpress database. The data indicated gene expression response to the implantation of drug (paclitaxel)-eluting or BMS in denuded human LIMA. Human LIMA was divided into three segments and two of the segments were fitted with either a PES or a BMS. The data includes three groups, control $(n=4), \operatorname{PES}(n=4)$, and BMS $(n=4)$.

Gene expression profiling was generated from the platform of (HG-U133_Plus_2) Affymetrix Human Genome U133 Plus 2.0 Array. The title was 'Gene expression response to implanted drug (paclitaxel)-eluting or BMS in denuded human LIMA'.

All the referred experiment samples were obtained with informed consent of the patients and verified by the Ethics Committee of the First Hospital of Zibo (Shandong, China).

Data preprocessing. To eliminate influences of nonspecific hybridization, background was corrected with RMA (17). After data were normalized with 'quantiles' (18), PM/MM correction was conducted with MAS method (19), and medianpolish was conducted for summarizing data (20).

According to the platform annotation files, probes were mapped to gene symbols. If more than one probe was mapped to a single gene, the mean level of probes was calculated as the final gene expression level. In total, 20,545 genes were obtained.

PPI network construction. PPI data were obtained from Search Tool for the Retrieval of Interacting Genes/Proteins database (http://string-db.org/) (21), including 15,186 genes and 181,789 interactions. We selected the PPI which contains the same genes with the microarray data for further analysis. In total, 14,194 genes and 166,370 PPI were obtained. After all the interactions were performed Pearson's correlation analysis, the edge with an absolute value more than $\delta(\delta=0.95)$ was selected, including 16,813 edges and 4,504 nodes. These edges were used to construct DCNs. Thus, two modules were obtained, module 1 indicating PES and 2 indicating BMS group. They had the same genes in the networks.

Each gene in the DCN was analyzed using one-sided t-test in the baseline and disease conditions. The weight was calculated using the following formula,

$$
\mathrm{w}_{i, j}= \begin{cases}\frac{\left(\log \mathrm{p}_{i}+\log \mathrm{p}_{j}\right)^{1 / 2}}{\left(2 * \max _{\mathrm{l} \in \mathrm{V}}\left|\log \mathrm{p}_{l}\right|\right)^{1 / 2}}, & \text { if } \operatorname{cor}(i, j) \geq \delta \\ 0, & \text { if } \operatorname{cor}(i, j)<\delta\end{cases}
$$

where $\mathrm{V}$ indicates the node set in the network, $\mathrm{p}_{\mathrm{i}}$ and $\mathrm{p}_{\mathrm{j}}$ are $\mathrm{P}$-values of differential expression for genes $\mathrm{i}$ and $\mathrm{j}$.

Identification of multiple differential modules. To identify M-DM, we adapted the recently developed M-module algorithm (13) to analyze genes in each DCN. It was generally divided in three steps, as described in the following.

Seed prioritization. For each network $\mathrm{G}=(\mathrm{V}, \mathrm{E})(1 \leq \mathrm{k} \leq \mathrm{M})$ with an adjacency matrix $\mathrm{A}=\left({ }_{\mathrm{aij}}\right)_{\mathrm{nx}}$, we applied a function to calculate the importance of gene $\mathrm{i}$ in the corresponding network,

$$
g(i)=\sum_{j \in N(i)} A_{i j}^{\prime} g(j)
$$

$g(i)=z$-score

where $\mathrm{N}(\mathrm{i})$ denotes the set of neighbors of gene $\mathrm{i}$ in $\mathrm{G}$; $\mathrm{A}^{\prime}$ denotes the degree normalized weighted adjacency matrix $\mathrm{A}^{\prime}=\mathrm{D}^{-1 / 2} \mathrm{AD} \mathrm{D}^{1 / 2}$ where $\mathrm{D}$ is the diagonal matrix of $\mathrm{A}$.

For each gene in DCN, after ranking genes according to the mean value of $\mathrm{z}$-score, we selected the top $1 \%$ genes as the seed genes. Finally, 45 seed genes were obtained.

Module search by seed expansion. For an indicated gene $\mathrm{v} \in \mathrm{V}$, it was considered as a differential module $\mathrm{C}$. The neighbors of gene $\mathrm{i}$ in the network was added to the module, generating a new module $\mathrm{C}^{\prime}$. Then we calculated the entropy for the connectivity of vertex i to $\mathrm{C}$ using the formula,

$$
\begin{gathered}
\mathrm{H}_{\mathrm{k}}\left(\mathrm{C}_{\mathrm{i}}\right)=-\mathrm{p}_{\mathrm{i}}^{[\mathrm{k}]} \log \mathrm{p}_{\mathrm{i}}^{[\mathrm{k}]}-\left(1-\mathrm{p}_{\mathrm{i}}^{[\mathrm{k}]}\right) \log \left(1-\mathrm{p}_{\mathrm{i}}^{[\mathrm{k}]}\right) \\
\mathrm{p}_{\mathrm{i}}^{[\mathrm{k}]}=\mathrm{L}_{\mathrm{k}}(\mathrm{i}) /\left(\overline{\mathrm{L}}_{\mathrm{k}}(\mathrm{i})+\mathrm{L}_{\mathrm{k}}(\mathrm{i})\right) \\
\mathrm{L}_{\mathrm{k}}(\mathrm{i})=\sum_{\mathrm{j} \neq \mathrm{i}, \mathrm{j} \in \mathrm{C}} \mathrm{a}_{\mathrm{ijk}}
\end{gathered}
$$

where $L_{k}(i)$ denotes total weight between gene $i$ and other gene in the module $C$ of network $G_{k} \cdot L_{K}(i)$ denotes the weight between gene $\mathrm{i}$ and genes outside of module $\mathrm{C}$.

$$
\mathrm{H}_{\mathrm{k}}(\mathrm{C})=\sum_{\mathrm{i} \in \mathrm{C}} \mathrm{H}\left(\mathrm{C}_{\mathrm{i}}\right)
$$

The entropy for $\mathrm{C}$ across all networks and normalized for the size of $\mathrm{C}$ is

$$
\mathrm{H}(\mathrm{C})=\left(\sum_{\mathrm{k}=1}^{\mathrm{M}} \mathrm{H}_{\mathrm{k}}(\mathrm{C})\right) /|\mathrm{c}|
$$

The connectivity variability between moule $\mathrm{C}$ and $\mathrm{C}^{\prime}$ was calculated according to $\mathrm{H}\left(\mathrm{C}^{\prime}, \mathrm{C}\right)=\mathrm{H}\left(\mathrm{C}^{\prime}\right)-\mathrm{H}(\mathrm{C})$.

If $\mathrm{H}\left(\mathrm{C}^{\prime}, \mathrm{C}\right)>0$, the gene $\mathrm{u}$ increased connectivity of module $\mathrm{C}$.

Then the neighbor genes which may increase $\mathrm{H}$ were added to the module $\mathrm{C}$.

Refinement of candidate modules. The M-modules with a size less than five were removed.

Overlapping M-modules with a Jaccard index more than 0.5 were merged to one module.

Finally, 38 candidate modules were identified.

Statistical significance of $M-D M s$. The statistical significance test was performed using the null score distribution of M-DMs. Randomly selected 16,813 from 166,370 edges and constructed a random network. After 100 times random construction, 5,154 modules were obtained. The empirical P-value of an M-DM was defined as the probability of the module having the observed score or smaller by chance. After corrected by Benjamini and Hochberg (22), an adjusted P-value $<0.05$ was considered to indicate a statistically significant difference. 
Table I. Seed genes were identified with average $\mathrm{z}$-score $>400$.

\begin{tabular}{llll}
\hline Node & z-score 1 & z-score 2 & Average \\
\hline CUL3 & 1069.576 & 978.9798 & 1024.278 \\
APP & 851.2247 & 829.1976 & 840.2112 \\
STAU1 & 588.7511 & 609.4044 & 599.0777 \\
SYNCRIP & 619.3264 & 523.9833 & 571.6549 \\
CUL7 & 395.7259 & 648.4051 & 522.0655 \\
CUL4B & 401.4574 & 602.1461 & 501.8017 \\
HNRNPR & 470.2798 & 346.0184 & 408.1491 \\
HSPA9 & 405.5541 & 407.5701 & 406.5621 \\
\hline
\end{tabular}

In total, 17 modules with $\mathrm{P}<0.05$ were identified as significant differential modules in each group.

Quantification of connectivity dynamics of shared M-DMs. Each M-DM with $\mathrm{M}>2$ has multiple component modules from different DCNs. The Module Connectivity Dynamic Score (MCDS) was applied to quantify the change in the connectivity of component modules.

For a given M-DM C whose adjacent matrices are denoted as

$$
\begin{gathered}
\Delta A_{i, i+1}^{C}=\left\|A_{i}^{C}-A_{i+1}^{C}\right\|_{2} /|C| \\
\tau\left(A^{C}\right)=\sum_{i=1}^{M-1} \Delta A_{i, i+1}^{C} /(M-1)
\end{gathered}
$$

where $\|\cdot\| 2$ is the matrix $L_{2}$ norm. $\tau\left(A^{C}\right)$ denotes the overall MCDS of an M-DM.

The statistical analysis is computed in similar way with that in M-DMs in Procedure 2.4. An adjusted P-value $<0.05$ was considered to indicate a statistically significant difference.

\section{Enrichment analysis of $M-D M s$}

Gene Ontology enrichment analysis. GO is a useful tool for collecting a large number of gene annotation terms (23). $\mathrm{P}=0.01$ was considered as a threshold value. Genes in M-DMs were enriched to GO category according to Biological Process function. After enrichment analysis, two significant modules were obtained, module 1 indicating PES and module 2 indicating BMS group.

Pathway enrichment analysis. Pathways were obtained from Kyoto Encyclopedia of Genes and Genomes (KEGG) pathway database (http://www.genome.jp/kegg/). Fisher's exact test was applied to identify pathways in the differential modules. The pathways with adjusted $\mathrm{P}<0.05$ were considered the enriched pathways in differential modules.

\section{Results}

DCNs construction. With the PPI data and microarray data, we selected the intersection set to construct DCNs using the edges at the criteria of Pearson's correlation coefficient $>0.95$. Two DCNs were obtained, with the same node set but different edge set, module 1 indicating PES and module 2 indicating BMS group.

$M-D M$ construction. Genes were calculated for the importance in DCNs. Based on the average of z-scores, the top $1 \%$ genes were selected as seed genes, in total 45 seed genes, of which eight genes were found with average scores $>400$, as shown in Table I.

With these seed genes, we performed module search and refinement, generating 38 modules. After statistical analysis, 17 candidate differential modules were obtained with adjusted $\mathrm{P}<0.05$. Then connectivity dynamics of M-DMs were quantified using MCDS. At an MCDS P-value cut-off of 0.05, two M-DMs were identified with a major change of connectivity (Table II). In module 1 (PES group), there were 142 nodes and 460 edges (Fig. 1). In module 2 (BMS group), there were 73 nodes and 222 edges (Fig. 2).

GO enrichment analysis. At the P-value cut-off of 0.05 , the enrichment of M-DMs genes in the GO biological process was obtained. In module 1 , the top 20 significant biological processes are presented in Fig. 3, of which RNA processing was the most significant enrichment of biological process and primary metabolic process was the highest enrichment of biological process. In module 2, the top 20 significant biological processes were presented in Fig. 4, of which nucleic acid metabolic was the most significant enrichment of biological and metabolic was the highest enrichment of biological process.

Pathway enrichment analysis. Following the KEGG pathway enrichment analysis for genes from M-DMs, significant KEGG terms were collected. In module 1, five significant pathways are identified, and Spliceosome pathway was the most significant enrichment of genes (Table III). In module 2, nine pathways were identified with adjusted $\mathrm{P}<0.05$, and Ubiquitin mediated proteolysis pathway was the most significant enrichment of genes (Table IV).

Table II. Two M-DMs were identified with a major change of connectivity.

\begin{tabular}{lccccc}
\hline & & & \multicolumn{2}{c}{ Adjusted P-value } \\
\cline { 5 - 6 } Module & Seed gene & Entropy & MCDS & Entropy & MCDS \\
\hline 1 & CUL7 & 0.766905 & 0.207211 & 0 & 0.034 \\
2 & CUL4B & 0.743426 & 0.277968 & 0 & 0.0069
\end{tabular}

M-MD, multiple differential module; MCDS, module connectivity dynamic score. 
Table III. KEGG pathway enrichment in module 1.

\begin{tabular}{llll}
\hline Pathways & P-value & Adjusted P-value & Genes \\
\hline $\begin{array}{l}\text { Spliceosome } \\
\text { PATH: hsa03040) }\end{array}$ & $1.84 \mathrm{E}-10$ & $2.50 \mathrm{E}-08$ & $\begin{array}{l}\text { ALYREF, DDX42, HNRNPA3, DHX15, } \\
\text { EFTUD2, EIF4A3, }\end{array}$ \\
& & & $\begin{array}{l}\text { HNRNPC, SF3A1, SF3B2, SF3B3, DDX23 } \\
\text { SNRNP70, RBM25, SNRPB }\end{array}$ \\
$\begin{array}{l}\text { Pathogenic Escherichia coli } \\
\text { infection (PATH: hsa05130) }\end{array}$ & $2.53 \mathrm{E}-06$ & 0.000171848 & EZR, KRT18, TUBA1B, TUBA4A, TUBB6 \\
$\begin{array}{l}\text { One carbon pool by folate } \\
\text { (PATH: hsa00670) }\end{array}$ & $6.64 \mathrm{E}-05$ & 0.003011209 & TUBB4B, YWHAZ, \\
$\begin{array}{l}\text { Non-homologous end-joining } \\
\text { (PATH: hsa03450) }\end{array}$ & 0.000377529 & 0.012835974 & ATIC, GART, MTHFD1, SHMT2 \\
$\begin{array}{l}\text { Phagosome } \\
\text { (PATH: hsa04145) }\end{array}$ & 0.001790718 & 0.048707539 & MRE11A, RAD50, XRCC5 \\
\end{tabular}

KEGG, Kyoto Encyclopedia of Genes and Genomes.

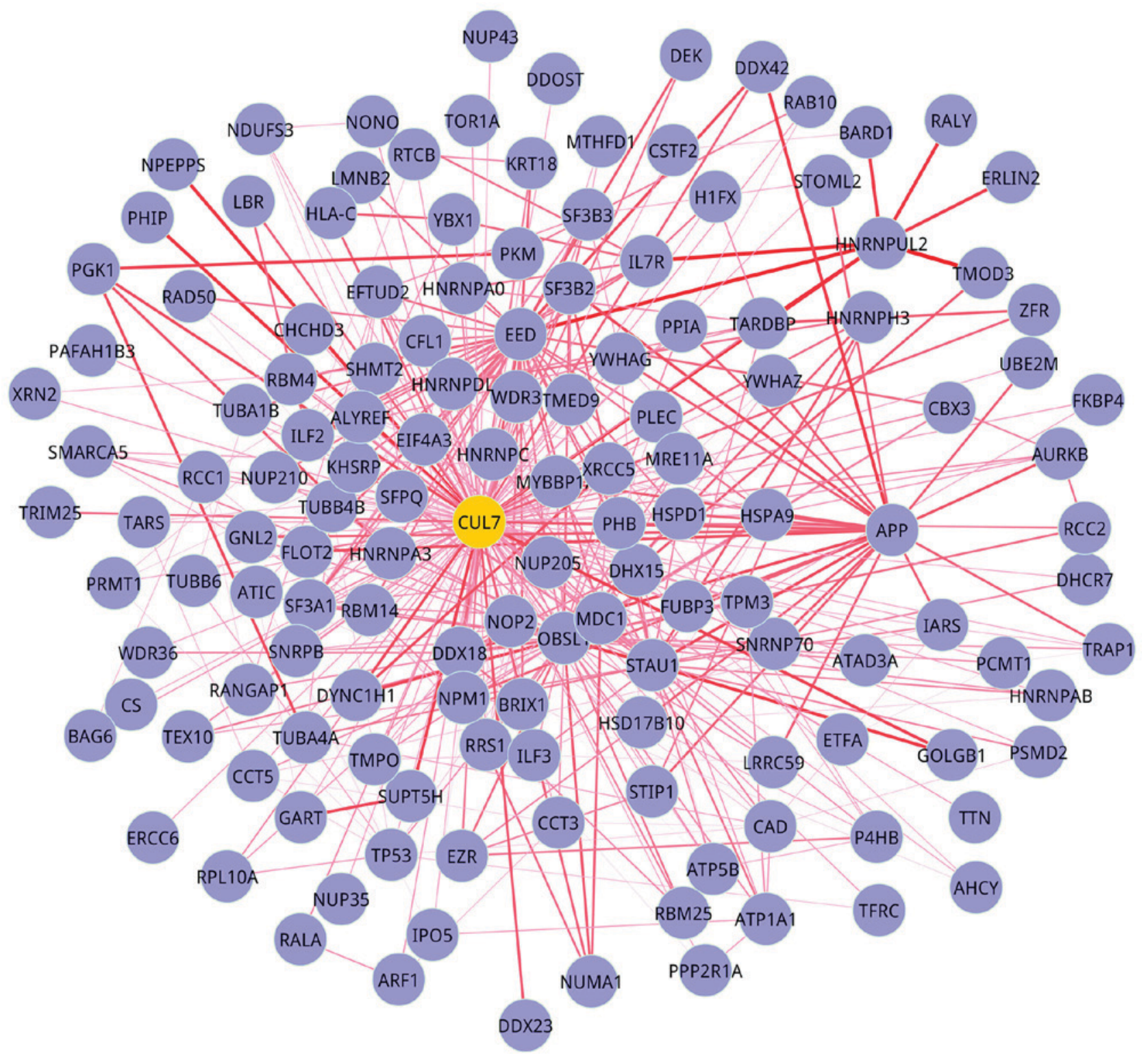

Figure 1. Module 1 identified in paclitaxel-eluting stent group. It includes 142 nodes and 460 edges. PES, paclitaxel-eluting stent. 


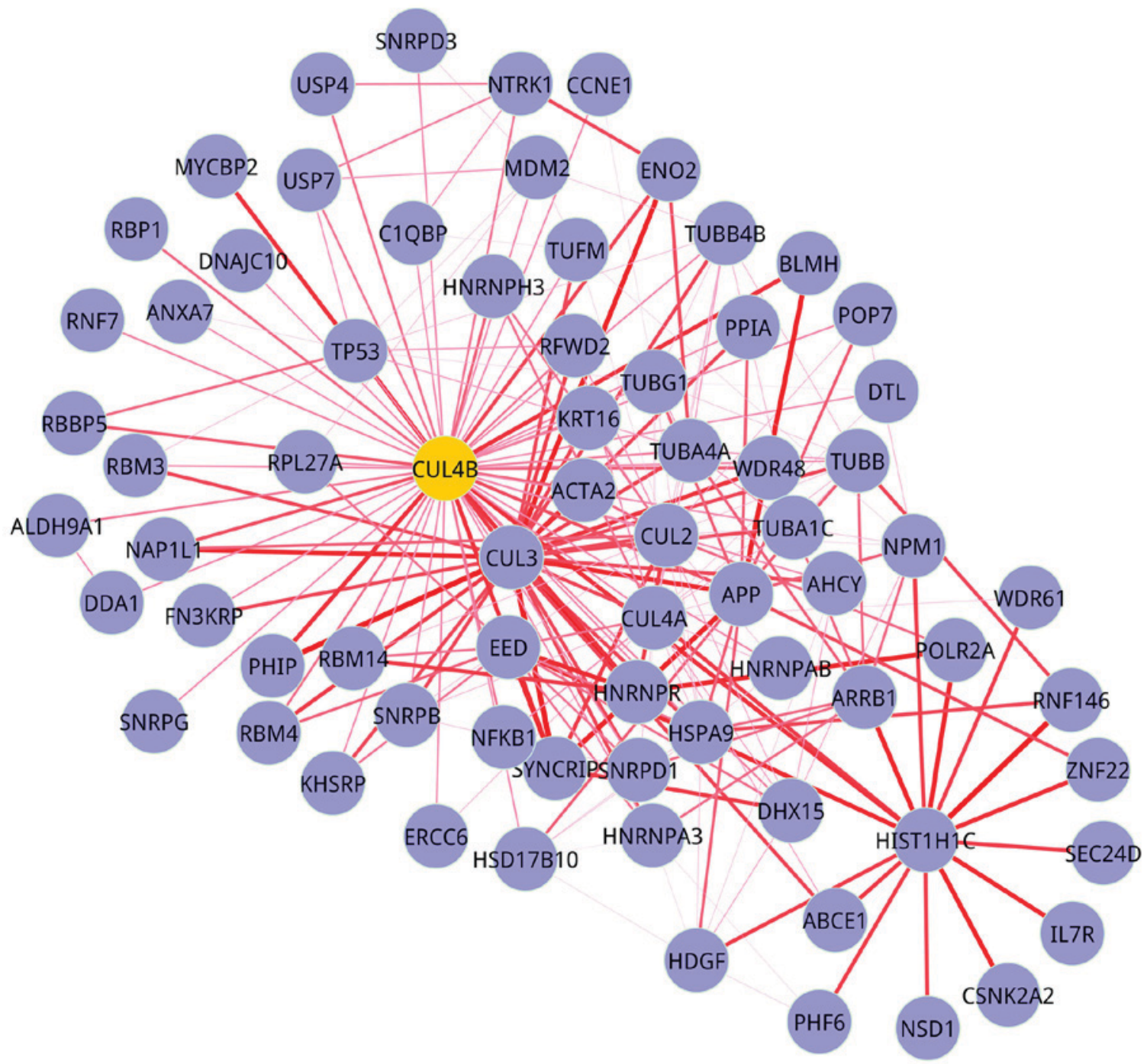

Figure 2. Module 2 identified in BMS group. It includes 73 nodes and 222 edges. BMS, bare-metal stents.

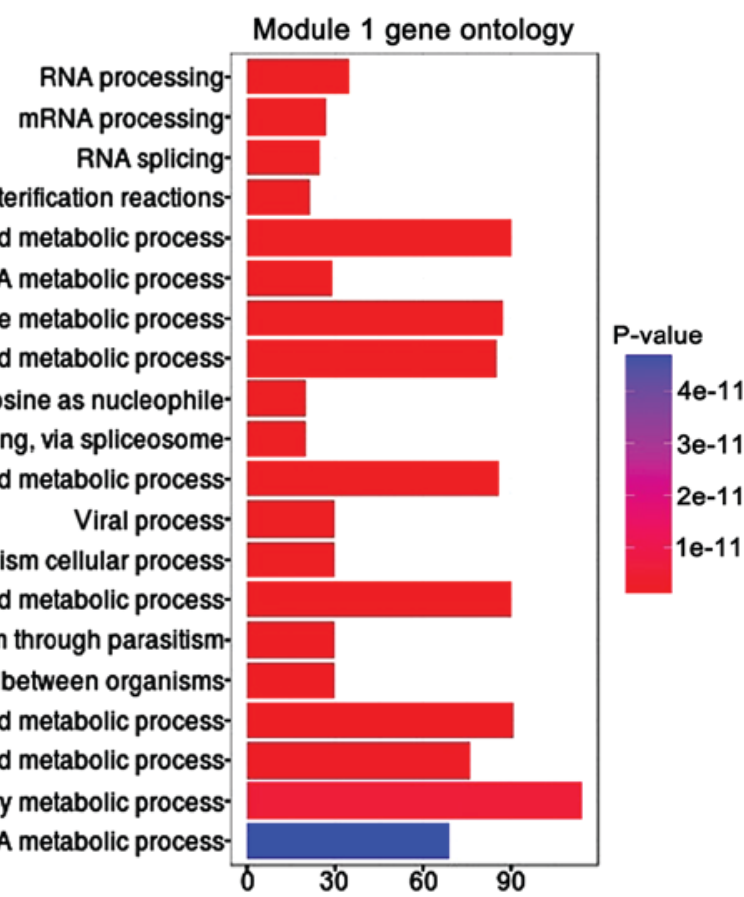

Figure 3. The top 20 significant biological processes obtained in module 1 . 
Table IV. KEGG pathway enrichment analysis in module 2.

\begin{tabular}{|c|c|c|c|}
\hline Pathways & P-value & Adjusted P-value & Genes \\
\hline $\begin{array}{l}\text { Ubiquitin mediated proteolysis } \\
\text { (PATH: hsa04120) }\end{array}$ & $1.55 \mathrm{E}-05$ & 0.001720119 & $\begin{array}{l}\text { CUL2, CUL3, CUL4A, CUL4B, } \\
\text { MDM2, RFWD2, RNF7 }\end{array}$ \\
\hline Spliceosome (PATH: hsa03040) & 0.000128525 & 0.00713315 & $\begin{array}{l}\text { DHX15, HNRNPA3, SNRPB, } \\
\text { SNRPD1, SNRPD3, SNRPG }\end{array}$ \\
\hline $\begin{array}{l}\text { Pathogenic Escherichia coli infection } \\
\text { (PATH: hsa05130) }\end{array}$ & 0.000319891 & 0.011835952 & TUBA1C, TUBA4A, TUBB, TUBB4B \\
\hline p53 signaling pathway (PATH: hsa04115) & 0.000721488 & 0.017621689 & CCNE1, MDM2, RFWD2, TP53 \\
\hline Herpes simplex infection (PATH: hsa05168) & 0.00079377 & 0.017621689 & $\begin{array}{l}\text { C1QBP, CSNK2A2, TP53, } \\
\text { POLR2A, NFKB1, USP7 }\end{array}$ \\
\hline Epstein-Barr virus infection (PATH: hsa05169) & 0.001254944 & 0.023216458 & $\begin{array}{l}\text { CSNK2A2, MDM2, TP53, } \\
\text { POLR2A, NFKB1, USP7 }\end{array}$ \\
\hline Gap junction (PATH: hsa04540) & 0.001972915 & 0.0273742 & TUBA1C, TUBA4A, TUBB, TUBB4B \\
\hline Prostate cancer (PATH: hsa05215) & 0.001972915 & 0.0273742 & CCNE1, MDM2, TP53, NFKB1 \\
\hline Nucleotide excision repair (PATH: hsa03420) & 0.002802581 & 0.034565169 & CUL4A, CUL4B, ERCC6 \\
\hline
\end{tabular}

KEGG, Kyoto Encyclopedia of Genes and Genomes.

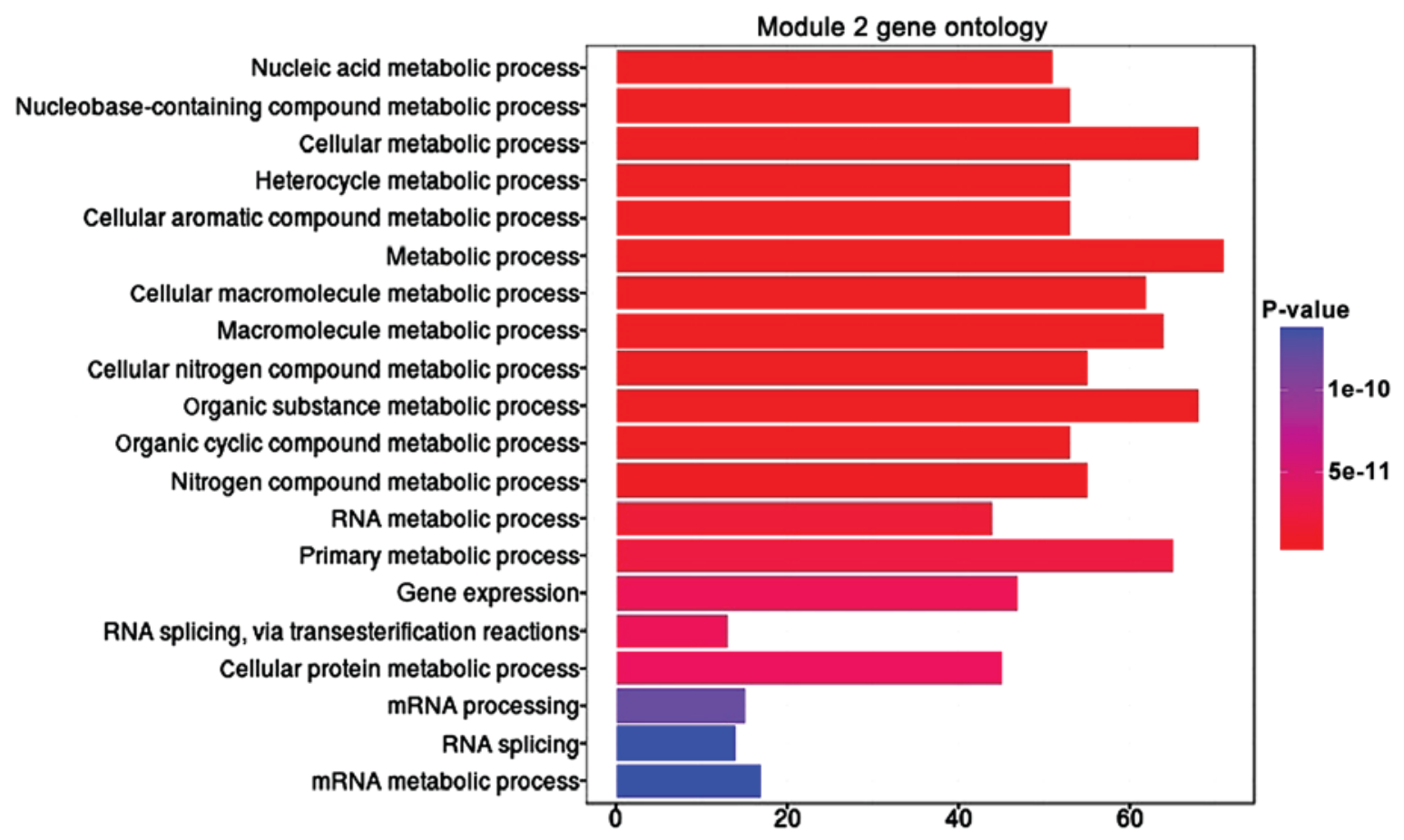

Figure 4. The top 20 significant biological processes obtained in module 2.

\section{Discussion}

BMS and DES are frequently used in medicine (2). The use of DES has been shown more effective than BMS in the reduction of restenosis (4). In the present study, we aimed to compare the putative molecular mechanism induced by PES and BES in denuded human LIMA arteries. We applied M-module algorithm to identify differential modules. Compared with control samples, in each stent group, one differential module was identified, named as module 1 (PES) and module 2 (BES).
The modules shared the same genes but with different interactions. After GO enrichment analysis, RNA processing was the most significant enrichment of biological process in module 1 and nucleic acid metabolic process was the most significant enrichment of biological process in module 2. Following the KEGG pathway enrichment analysis, five significant pathways were identified in module 1 and nine significant pathways were identified in 2 . These identified significant modules and pathways may reveal potential molecular mechanisms between PES and BES in denuded human LIMA arteries. 
In the coronary artery lesions, DES have successfully decreased the rate of in-stent restenosis and target lesion revascularization compared with BMS $(4,24)$. The amount of NIH at 6 months after stent implantation was significantly smaller in the PES than that identified than in the BMS group (25). While in the present study, we tried to explore the molecular differences between the two groups by identifying differential co-expressed networks.

Changes in the structure and activity of gene network play a critical role in the disease progression. In the present study, we applied iMDM algorithm to explore differential co-expressed modules. This iMDM algorithm has been used in the time-course RNA-Seq dataset generated using a murine heart failure model generated on two genotypes (13), which achieved higher accuracy in inferring gene modules compared to using single or multiple co-expression networks. This method showed better performance in quantifying genes and edges in a module compared with traditional studies, such as hub genes, which only focused on highly connected genes in a pathway $(26,27)$. With this method, two modules were identified after comparing stent-treatment samples to control samples. Different significant biological processes and KEGG pathways were found in these modules, indicating that PES and BMS induced different molecular changes in human LIMA arteries.

There are some limitations in this study. The number of samples were too small in the study. That is not sufficient to obtain a conclusion. Still, the PES is rarely used in US due to the superiority of second-generation stents (zotarolimusand everolimus-eluting stents), thus we will perform further analysis of second-generation stents.

In conclusion, each stent-treated group was identified with a module, and different significant biological processes and different significant pathways were mediated by the two stent types. Thus through these modules, we revealed the potential molecular changes induced by PES and BMS, which provide new insights into the underlying mechanisms in human LIMA arteries after inserted with a stent.

\section{Acknowledgements}

Not applicable.

\section{Funding}

No funding was received.

\section{Availability of data and materials}

The datasets used and/or analyzed during the current study are available from the corresponding author on reasonable request.

\section{Authors' contributions}

$\mathrm{ZT}$ as the first and corresponding author contributed to the conception and design of the study; JG as the second author contributed significantly to analysis and manuscript preparation; PS as the third author performed the data analyses and wrote the manuscript; JZ and YZ as the fourth and fifth authors helped perform the analysis with constructive discussions. All authors read and approved the final manuscript.

\section{Ethics approval and consent to participate}

The Ethics Committee of The First Hospital of Zibo approved the research, and written informed consent was given by all participants.

\section{Consent for publication}

Not applicable.

\section{Competing interests}

The authors declare that they have no competing interests.

\section{References}

1. Ruygrok PN and Serruys PW: Intracoronary stenting. From concept to custom. Circulation 94: 882-890, 1996.

2. Bønaa KH, Mannsverk J, Wiseth R, Aaberge L, Myreng Y, Nygård $\mathrm{O}$, Nilsen DW, Kløw NE, Uchto M, Trovik T, et al; NORSTENT Investigators: Drug-eluting or bare-metal stents for coronary artery disease. N Engl J Med 375: 1242-1252, 2016.

3. Serruys PW, Kutryk MJ and Ong AT: Coronary-artery stents. N Engl J Med 354: 483-495, 2006.

4. Moses JW, Leon MB, Popma JJ, Fitzgerald PJ, Holmes DR, O'Shaughnessy C, Caputo RP, Kereiakes DJ, Williams DO, Teirstein PS, et al; SIRIUS Investigators: Sirolimus-eluting stents versus standard stents in patients with stenosis in a native coronary artery. N Engl J Med 349: 1315-1323, 2003.

5. Laarman GJ, Suttorp MJ, Dirksen MT, van Heerebeek L, Kiemeneij F, Slagboom T, van der Wieken LR, Tijssen JG, Rensing BJ and Patterson M: Paclitaxel-eluting versus uncoated stents in primary percutaneous coronary intervention. N Engl J Med 355: 1105-1113, 2006.

6. Authors/Task Force m, Windecker S, Kolh P, Alfonso F, Collet JP, Cremer J, Falk V, Filippatos G, Hamm C, Head SJ, et al: 2014 ESC/EACTS Guidelines on myocardial revascularization: The Task Force on Myocardial Revascularization of the European Society of Cardiology (ESC) and the European Association for Cardio-Thoracic Surgery (EACTS)Developed with the special contribution of the European Association of Percutaneous Cardiovascular Interventions (EAPCI). Eur Heart J 35: 2541-2619, 2014.

7. Huan T, Zhang B, Wang Z, Joehanes R, Zhu J, Johnson AD, Ying S, Munson PJ, Raghavachari N, Wang R, et al; Coronary artery disease genome wide replication and meta-analysis (CARDIoGRAM) consortium, International Consortium for Blood Pressure GWAS (ICBP): A systems biology framework identifies molecular underpinnings of coronary heart disease. Arterioscler Thromb Vasc Biol 33: 1427-1434, 2013.

8. Gargalovic PS, Imura M, Zhang B, Gharavi NM, Clark MJ, Pagnon J, Yang WP, He A, Truong A, Patel S, et al: Identification of inflammatory gene modules based on variations of human endothelial cell responses to oxidized lipids. Proc Natl Acad Sci USA 103: 12741-12746, 2006.

9. Akavia UD and Benayahu D: Meta-analysis and profiling of cardiac expression modules. Physiol Genomics 35: 305-315, 2008.

10. Segal E, Shapira M, Regev A, Pe'er D, Botstein D, Koller D and Friedman N: Module networks: Identifying regulatory modules and their condition-specific regulators from gene expression data. Nat Genet 34: 166-176, 2003.

11. Tanay A and Shamir R: Computational expansion of genetic networks. Bioinformatics 17 (Suppl 1): S270-S278, 2001.

12. Pe'er D, Regev A and Tanay A: Minreg: Inferring an active regulator set. Bioinformatics 18 (Suppl 1): S258-S267, 2002.

13. MaX, Gao L, Karamanlidis G, Gao P,Lee CF, Garcia-Menendez L, Tian $\mathrm{R}$ and Tan $\mathrm{K}$ : Revealing pathway dynamics in heart diseases by analyzing multiple differential networks. PLOS Comput Biol 11: e1004332, 2015. 
14. Nayak RR, Kearns M, Spielman RS and Cheung VG: Coexpression network based on natural variation in human gene expression reveals gene interactions and functions. Genome Res 19: 1953-1962, 2009.

15. Vizeacoumar FJ, van Dyk N, S Vizeacoumar F, Cheung V, Li J, Sydorskyy Y, Case N, Li Z, Datti A, Nislow C, et al: Integrating high-throughput genetic interaction mapping and high-content screening to explore yeast spindle morphogenesis. J Cell Biol 188: 69-81, 2010.

16. Xiao Y, Xu C, Guan J, Ping Y, Fan H, Li Y, Zhao H and Li X: Discovering dysfunction of multiple microRNAs cooperation in disease by a conserved microRNA co-expression network. PLoS One 7: e32201, 2012.

17. Ma L, Robinson LN and Towle HC: ChREBP*Mlx is the principal mediator of glucose-induced gene expression in the liver. J Biol Chem 281: 28721-28730, 2006.

18. Rifai N and Ridker PM: Proposed cardiovascular risk assessment algorithm using high-sensitivity C-reactive protein and lipid screening. Clin Chem 47: 28-30, 2001

19. Bolstad BM, Irizarry RA, Astrand M and Speed TP: A comparison of normalization methods for high density oligonucleotide array data based on variance and bias. Bioinformatics 19: 185-193, 2003.

20. Irizarry RA, Bolstad BM, Collin F, Cope LM, Hobbs B and Speed TP: Summaries of affymetrix genechip probe level data. Nucleic Acids Res 31: e15, 2003.

21. Szklarczyk D, Franceschini A, Kuhn M, Simonovic M, Roth A, Minguez P, Doerks T, Stark M, Muller J, Bork P, et al: The STRING database in 2011: Functional interaction networks of proteins, globally integrated and scored. Nucleic Acids Res 39 (Database): D561-D568, 2011.
22. Benjamini Y and Hochberg Y: Controlling the false discovery rate: A practical and powerful approach to multiple testing. J R Stat Soc B 57: 289-300, 1995.

23. Ashburner M, Ball CA, Blake JA, Botstein D, Butler $\mathrm{H}$, Cherry JM, Davis AP, Dolinski K, Dwight SS, Eppig JT, et al; The Gene Ontology Consortium: Gene ontology: Tool for the unification of biology. Nat Genet 25: 25-29, 2000.

24. Stettler C, Wandel S, Allemann S, Kastrati A, Morice MC, Schömig A, Pfisterer ME, Stone GW, Leon MB, de Lezo JS, et al: Outcomes associated with drug-eluting and bare-metal stents: A collaborative network meta-analysis. Lancet 370: 937-948, 2007.

25. Miki K, Fujii K, Kawasaki D, Fukunaga M, Nishimura M, Horimatsu T, Saita T, Tamaru H, Imanaka T, Shibuya M, et al: Effect of bare-metal nitinol stent implantation and paclitaxel-eluting nitinol stent implantation on vascular response in the superficial femoral artery lesion assessed on intravascular ultrasound. Circ J 78: 1451-1458, 2014.

26. Taylor IW, Linding R, Warde-Farley D, Liu Y, Pesquita C, Faria D, Bull S, Pawson T, Morris Q and Wrana JL: Dynamic modularity in protein interaction networks predicts breast cancer outcome. Nat Biotechnol 27: 199-204, 2009.

27. Pujana MA, Han JD, Starita LM, Stevens KN, Tewari M, Ahn JS, Rennert G, Moreno V, Kirchhoff T, Gold B, et al: Network modeling links breast cancer susceptibility and centrosome dysfunction. Nat Genet 39: 1338-1349, 2007.

This work is licensed under a Creative Commons

Attribution-NonCommercial-NoDerivatives 4.0 International (CC BY-NC-ND 4.0) License. 